\title{
Examination of Blood-Brain Barrier (BBB) Integrity In A Mouse Brain Tumor Model
}

\author{
Ngoc On ${ }^{1}$, Ryan Mitchell ${ }^{1}$, Sanjot D. Savant ${ }^{2}$, Corbin. J. Bachmeier ${ }^{2}$, Grant M. Hatch ${ }^{1}$, and \\ Donald W. Miller ${ }^{1}$ \\ ${ }^{1}$ Department of Pharmacology and Therapeutics, University of Manitoba, 753 McDermot Ave., \\ Winnipeg, MB, CANADA, R3E OT6 (N.O., R. M., G.H., and D.W.M.) \\ ${ }^{2}$ Department of Pharmaceutical Sciences, University of Nebraska Medical Center, 986025 \\ Nebraska Medical Center, Omaha, NE 68198-6025 (S.D.S. and C.J.B.)
}

\begin{abstract}
The present study evaluates, both functionally and biochemically, brain tumor-induced alterations in brain capillary endothelial cells. Brain tumors were induced in Balb/c mice via intracranial injection of Lewis Lung carcinoma (3LL) cells into the right hemisphere of the mouse brain using stereotaxic apparatus. Blood-brain barrier (BBB) permeability was assessed at various stages of tumor development, using both radiolabeled tracer permeability and magnetic resonance imaging (MRI) with gadolinium diethylene-triamine-pentaacetate contrast enhancement (Gad-DTPA). The expression of the drug efflux transporter, P-glycoprotein (P-gp), in the BBB at various stages of tumor development was also evaluated by Western blot and immunohistochemistry. Median mouse survival following tumor cell injection was 17 days. The permeability of the BBB to ${ }^{3} \mathrm{H}-$ mannitol was similar in both brain hemispheres at 7 and 10 days post-injection. By day 15, there was a 2 -fold increase in ${ }^{3} \mathrm{H}$-mannitol permeability in the tumor bearing hemispheres compared to the non-tumor hemispheres. Examination of BBB permeability with Gad-DTPA contrast enhanced MRI indicated cerebral vascular permeability changes were confined to the tumor area. The permeability increase observed at the later stages of tumor development correlated with an increase in cerebral vascular volume suggesting angiogenesis within the tumor bearing hemisphere. Furthermore, the Gad-DPTA enhancement observed within the tumor area was significantly less than Gad-DPTA enhancement within the circumventricular organs not protected by the BBB. Expression of P-gp in both the tumor bearing and non-tumor bearing portions of the brain appeared similar at all time points examined. These studies suggest that although BBB integrity is altered within the tumor site at later stages of development, the BBB is still functional and limiting in terms of solute and drug permeability in and around the tumor.
\end{abstract}

\section{Keywords}

Blood Brain Barrier (BBB); Brain Tumor; Permeability; P-glycoprotein; Magnetic Resonance Imaging (MRI); Lewis Lung Carcinoma (3LL)

\section{INTRODUCTION}

The incidence of brain metastasis is increasing, with an estimated 170,000 new cases of brain metastasis diagnosed annually in the U.S. [1]. This increase is due in part to superior

Address correspondence to: Donald W. Miller, Ph.D., Department of Pharmacology and Therapeutics, University of Manitoba, 753 McDermot Ave., Winnipeg, MB, R3E 0T6, CANADA, miller5@cc.umanitoba.ca, Phone: 204-789-3278, FAX: 402-789-3932. 
diagnostic techniques and to better treatment regimens for peripheral tumors, resulting in longer survival times for patients with peripheral tumors and therefore increased risk of developing brain metastasis. Of the solid organ tumors, lung cancer accounts for approximately $50 \%$ of brain metastases [2]. The clinical impact of brain metastases in lung cancer is such that intracranial metastasis is present in an estimated 10-20\% of small cell lung cancer patients at initial diagnosis and in $80 \%$ of patients at autopsy [3].

While improvements in both drug design and drug dosing have resulted in significant advances in cancer treatment, brain tumor responsiveness to chemotherapy remains poor [4]. One of the primary reasons for this could be the specialized capillary endothelial cells that form the blood-brain barrier (BBB). An intact BBB represents a challenge to the effective delivery of chemotherapeutic agents. This is due to the tight cellular junctions, reduced pinocytic activity and absence of fenestrations that are characteristic of the brain endothelial cells that form the BBB [5]. Furthermore, the expression of efflux tranporters such as Pglycoprotein (P-gp), multidrug-resistance associated proteins (MRPs), and breast cancer resistance protein (BCRP), within the brain microvessel endothelial cells act to further restrict the distribution of a wide variety of chemotherapeutic agents in brain $[6,7]$.

It has been suggested that BBB integrity is compromised in brain tumors [8]. However, more recent data suggest that BBB permeability is heterogeneous within the tumor site and is dependent on the type of tumor and stage of tumor development $[8,9]$. In the present study, a murine brain tumor model was used to comprehensively examine BBB function throughout tumor development. Blood-brain barrier integrity was examined at various stages of tumor development using both vascular permeability tracers as well as magnetic resonance imaging (MRI). The data suggest that the BBB remains intact throughout the early and intermediate stages of tumor development, with significant increases in BBB permeability occurring only during the final stages of tumor progression. The permeability increases appear to be confined to the tumor area as BBB integrity in non-tumor regions remained intact. Furthermore, even within the confines of the brain tumor, vascular permeability was still reduced compared to that observed in the circumventricular organs outside of the BBB. Finally, expression of the drug efflux transporter protein, P-gp, in cerebral microvascular endothelial cells was present in both normal brain tissue and brain tumor tissue. These studies indicate that BBB is still an obstacle for delivery of chemotherapeutic agents and highlights the need for approaches that enhance the delivery of chemotherapeutic agents in the brain.

\section{MATERIALS AND METHODS}

\section{Animals and tumor model}

Female inbred Balb/c mice were used for the brain tumor model. Mice (15-20 g) were purchased from Charles River Laboratories (Wilmington, MA) and fed a standard laboratory diet ad libitum. Mice were anesthetized and placed in a stereotaxic apparatus (Kopf instruments) for intracerebral implantation of the Lewis Lung Carcinoma (3LL) cells. A total of 5000 3LL cells were suspended in $7.5 \mu \mathrm{l}$ of buffer and injected slowly over a 3minute period into the right hemisphere at a depth of $4 \mathrm{~mm}, 2 \mathrm{~mm}$ posterior of the bregma and $1 \mathrm{~mm}$ lateral of the coronal suture using a $25 \mu \mathrm{l}$ Hamilton syringe fitted with a 31-gauge beveled needle. Mice were allowed to recover from anesthesia undisturbed before being returned to their respective cages. A total of 31 mice were used for the tumor progression, survival and immunohistological studies, while 40 mice were used to assess BBB permeability during tumor progression. All animal studies were done in accordance with protocols approved by the Institutional Animal Care and Use Committee (IACUC). 


\section{Survival analysis}

Following tumor cell implantation, mice were provided food and water ad libitum and monitored daily for signs of tumor growth and progression. Tumor survival studies were performed using humane endpoints including loss of locomotor activity, and weight loss (up to $25 \%$ ). The survival time was measured from the day of tumor cell implantation to the day of euthanasia or death and median mouse survival time was calculated.

\section{Assessment of Tumor Volume}

For the tumor volume studies, mice were sacrificed on day 7, 10, 12, and 15 post-tumor injection. The brains were removed and fixed with formaldehyde $4 \% \mathrm{w} / \mathrm{v}$ (FormaldeFresh $^{\circledR}$, Fisher Scientific). A series of coronal sections of the brain were made at $1 \mathrm{~mm}$ intervals and blocked in paraffin. Brain slices $(6 \mu \mathrm{m})$ were cut from each serial section using a freezing microtome, and stained with hematoxylin and eosin (H \& E) dye. The H \& E stained slices were scanned and tumor volume determined based on serial slices from the captured images using a computer image analysis system (Image J; NIH, Bethesda, MD). The area analyzed spanned from $5 \mathrm{~mm}$ rostral to $5 \mathrm{~mm}$ caudal from the site of tumor cell injection.

In separate studies tumor volume was examined within the same mouse at 7, 12, and 15-day post tumor cell implantation using MRI techniques. Mice were anesthetized and secured in a Biospec 7T/21 cm spectrometer magnet (Bruker; Karlsruhe, Germany) equipped with Paravision 3.0 software. Coronal images of brain were obtained using T2-weighted spin echo (SE) pulse sequences with the following parameters: repetition time (TR) / echo time $(\mathrm{TE})=164000 / 20.00$ milliseconds, slice thickness of $0.75 \mathrm{~mm}, \mathrm{FOV}=2.5 \times 2.5 \mathrm{~cm}^{2}$, averages $=12$, matrix size $=256 \times 256$, and resolution of $117 \times 117 \mu \mathrm{m}^{2}$. Quantitative analyses of tumor volume were performed by visually locating the tumor lesion on the T2weight images and tumor volume was calculated from the selected regions of interest (ROI) from serial slices using Marevisi 3.5 software (Institute for Biodiagnostics, National Research Council, Canada).

\section{Assessment of blood- barrier permeability}

In order to establish the effect of tumor growth on the permeability of the blood-brain barrier (BBB), cerebrovascular leakage of ${ }^{3} \mathrm{H}$-mannitol, a low molecular weight marker (182.17 Da), and Evan's Blue (EB), a high molecular weight marker (approximately 65,000 Da) was evaluated $7,10,12$, and 15 days after tumor implantation. Mice $(n=9)$ were anesthetized with ketamine $(30 \mathrm{mg} / \mathrm{ml}) / x y l a z i n e ~(4 \mathrm{mg} / \mathrm{ml})$ and a phosphate buffered saline solution containing ${ }^{3} \mathrm{H}$ mannitol ( $4 \mu \mathrm{Ci} /$ mouse) and Evan's Blue ( $\left.2 \% \mathrm{w} / \mathrm{v}\right)$ was administered via bolus tail vein injection. After ten minutes, blood samples were taken, the mouse sacrificed and brain samples removed. The right (tumor-bearing) and left (non-tumor bearing) brain hemispheres were separated and weighed. Capillary depletion was performed as described below. Samples $(200 \mu \mathrm{l})$ were taken from the capillary depleted fractions and plasma and analyzed for ${ }^{3} \mathrm{H}$ mannitol using a liquid scintillation counter (Packard $2500 \mathrm{TR} / \mathrm{AB}$ ). Values were expressed as the brain to plasma ratio. Evan's Blue concentrations in the capillary depleted samples were determined spectrophotometrically. In brief, $200 \mu \mathrm{l}$ samples were mixed with a 50\% trichloroacetic acid solution (1:1 volume) and the resulting absorption measured at $610 \mathrm{~nm}$ using a Shimadzu (UV-3600) spectrophotometer.

Vascular integrity within the tumor at various stages of development, was also assessed using gadolinium contrast enhanced MRI. Vascular integrity of tumor mice and non-tumor mice (control mice) was examined prior to implantation (pre tumor injection) and on day 7 , 12 , and 15 post injection of tumor cells or vehicle, respectively, using gadolinium contrast enhanced MRI. For these studies, T1-weighted images were obtained using the same 7T 
magnetic described previously with the following parameters: repetition time of $750 \mathrm{msec}$, an echo time of $11.6 \mathrm{msec}$, a slice thickness of $0.75 \mathrm{~mm}$, FOV was $2.5 \times 2.5 \mathrm{~cm}^{2}$, averages = 12 , matrix size was $256 \times 256$, and resolution was $117 \times 117 \mu \mathrm{m}^{2}$. Two sets of T1-weighted images were obtained. The first scan was done in the absence of Gadolinium diethylenetriaminepentaacetate contrast agent (Gad-DTPA). A second T1-weighted imaging scan was performed 10 minutes following an intravenous bolus injection of $0.4 \mathrm{mmol} / \mathrm{kg}$ of Gad-DTPA. The intensity of Gad-DTPA in the brain and at the tumor site was determined by the percent difference in pre and post-Gad-DTPA images according to the following formula using Paravision 3.0 software:

(Post-Gad-DTPA intensity from T1-weighted images - Pre-Gad-DTPA intensity from T1weighted images) $\div$ Pre-Gad-DTPA intensity from T1-weighted images X 100 . Quantification of Gad-DTPA was accomplished by manually placing the ROI over either tumor or various non-tumor regions using Marevisi 3.5 software (Institute for Biodiagnostics, National Research Council, Canada). For non-tumor regions, areas were selected contralateral to the tumor site. In addition, Gad DTPA contrast enhancement was examined in the left lateral ventricle to compare the changes in cerebral vascular permeability within the tumor site to vascular permeability in the circumventricular brain regions that lie outside the BBB. As the circumventricular organs are highly vascularized sites positioned at discrete regions around the ventricular system [10], and the lateral ventricles are easily identified and located on MRI scans, the left (non-tumor) lateral ventricle was selected to assess permeability within circumventricular organs that have an incomplete BBB.

\section{Capillary Depletion}

For the assessment of BBB permeability, determination of angiogenesis, and examination of P-gp expression, capillary depletion was performed as described [11]. Briefly, mice were sacrificed on various days post tumor cell injection (7-15 days). Sham mice receiving only intracranial injections of culture media were sacrificed on day 15 post-media injection. After the brain was removed, the right and left hemispheres were separated and weighed. The hemispheres were homogenized using a glass homogenizer in five times the volume of physiological buffer (HEPES $10 \mathrm{mM}, \mathrm{NaCl} 141 \mathrm{mM}, \mathrm{KCl} 4 \mathrm{mM}, \mathrm{CaCl}_{2} 2.8 \mathrm{mM}, \mathrm{MgSO}_{4} 1$ $\mathrm{mM}, \mathrm{NaH}_{2} \mathrm{PO}_{4} 1 \mathrm{mM}$, and D-glucose $10 \mathrm{mM}$ ) and $13 \%$ dextran. The homogenate was then centrifuged at $5400 \times \mathrm{g}$ for 15 minutes at $4^{\circ} \mathrm{C}$. The pellet containing the brain capillary endothelial cells was carefully separated from the supernatant containing brain parenchyma. For those mice receiving radiolabeled mannitol, aliquots $(200 \mu \mathrm{l})$ from both the supernatant and pellet fractions were analyzed using a liquid scintillation counter (Packard $2500 \mathrm{TR} / \mathrm{AB}$ ) to measure BBB permeability and cerebral vascular volume. The amount of ${ }^{3} \mathrm{H}$-mannitol in the supernatant samples was indicative of tracer having passed through the BBB. The amount of radiolabeled mannitol retained in the brain capillary pellet was used to assess cerebrovascular volume. In both cases, the radioactivity in supernatant and pellet fractions was normalized based on the total activity present in the plasma. The protein content of the resulting capillary pellet from both the tumor-injected right hemisphere and non-tumor containing left hemisphere on days 7, 10,12, and 15-post tumor injection was determined using the BCA method (Pierce, Rockford, IL).

\section{Western blot analysis of P-glycoprotein}

Cell lysates from the capillary-enriched pellet and capillary-depleted supernatant were denatured by heating at $95^{\circ} \mathrm{C}$ for 5 minutes and loaded onto $7.5 \%$ polyacrylamide gels (BioRad, Hercules, CA). Electrophoresis of the molecular weight marker and samples was performed under a constant voltage $(40 \mathrm{~V})$ at room temperature for approximately 3 hours. The protein bands were transferred to Millipore polyvinylidene fluoride (PVDF) membranes 
by applying a constant current of $240 \mathrm{~mA}$ for 1 hour at $4^{\circ} \mathrm{C}$. Membranes were washed and incubated with $0.3 \%$ Tween-20 and $1 \%$ BSA to block non-specific binding sites on the membrane. The expression of P-gp protein was identified using P-gp antibody (Kamiya Biomedical, Seattle, WA). The membrane was exposed to primary antibodies overnight at $4^{\circ} \mathrm{C}$. After washing, the membrane was incubated with a secondary horseradish peroxidase antimouse Ig antibody (1:1500 dilution; Amersham Life Sciences, Cleveland, OH). The specific protein band was visualized using a chemiluminescence kit (Pierce, Rockford, IL). Expression of P-gp was performed on pooled samples from left (non-tumor) and right (tumor) brain hemisphere of mice at various stages of tumor development.

\section{Immunohistochemical Detection of P-glycoprotein}

Coronal brain slices $(6 \mu \mathrm{m})$ were prepared as described above from formalin-fixed and paraffin embedded brain sections and mounted onto glass slides. After drying, slides were submerged in xylene solution to remove paraffin and re-hydrated in a series of 5 minute washes in 100, 90, 80, 70 and 0\% ethanol solution. Formalin cross-links were removed by gently boiling slides in citric acid $(4 \mathrm{mg} / \mathrm{ml})$ and sodium citrate $(1 \mathrm{mg} / \mathrm{ml})$ solution for 40 minutes. Slides were cooled and rinsed with $5 \mathrm{mM}$ Tris buffer and endogenous peroxidase activity was blocked using $3 \% \mathrm{H}_{2} \mathrm{O}_{2}$ for 10 minutes at room temperature. Brain slices were exposed to blocking buffer (10\% goat serum in phosphate buffered saline (PBS) solution with $1 \%$ bovine serum albumin) for 30 minutes at room temperature. To minimize nonspecific binding of the primary antibody, slides were incubated for an additional 60 minutes at room temperature with a 1:10 dilution of unconjugated goat-anti-mouse $\operatorname{IgG}$ in phosphate buffered saline containing $1 \%$ bovine serum albumin. Slides were washed and incubated at $4^{\mathrm{O}} \mathrm{C}$ overnight in phosphate buffered saline solution containing primary $\mathrm{C} 219$ antibody (1:40 dilution). After washing, secondary antibody (biotin-SP-conjugated goat-anti-mouse $\mathrm{IgG}$ ) was added at a dilution of 1:500 for 20 minutes at room temperature. Slides were washed and incubated for 20 minutes at room temperature with 1:500 dilution of HRPStreptavidin (Vector Labs; location). Brain slices were stained with DAB and counterstained with haematoxylin.

\section{Statistical analysis}

Statistical analysis of BBB permeability and cerebral vascular volume was evaluated using the paired Student's t-test. The values of left (non-tumor bearing) hemisphere were compared with the values in right (tumor bearing) hemisphere. Changes in tumor volume and GAD-DTPA enhancement were analyzed using ANOVA.

\section{RESULTS}

\section{Survival studies and tumor progression}

All mice injected with 3LL cells developed brain tumors (Fig.1). Using humane endpoints in determination of survival time, mice implanted with 3LL tumor cells survived a median of 17 days (Fig.1). The progression of the tumor was rapid with $100 \%$ of the mice surviving to 15 days post-tumor cell implantation, however none of the mice survived past day 19 (Fig. 1). The earliest outward sign of tumor burden typically occurred within 10 days postinnoculation and was manifested as weight loss ( $<10 \%$ body weight). This was followed by a period of $1-4$ days of further weight loss, hunchback posture, and diminished locomotor activity. Based on the survival studies, additional mice were examined for tumor development using both MRI and histochemical analysis. Tumor was consistently evident microscopically 7 days after tumor implantation in mice. Both qualitative (histological) and quantitative (tumor volume estimates) examination of tumor progression indicates a rapidly expanding tumor area in the brain, reaching $2 \pm 1 \mathrm{~mm}^{3}$ and $30 \pm 12 \mathrm{~mm}^{3}$ by day 7 and 12 post-tumor cell implantation, respectively (Fig.2). By day 15, there was a widely visible 
tumor mass present that occupied as much as $75 \%$ of the right brain hemisphere and had reached a volume of approximately $77 \pm 28 \mathrm{~mm}^{3}$ (Fig.2).

The impact of tumor growth on cerebral vascular angiogenesis was determined by measuring both the protein and ${ }^{3} \mathrm{H}$-mannitol content in the capillary pellet from the tumorbearing right brain hemisphere and the non-tumor bearing left hemisphere at various days during tumor development. At days 7 and 10 post tumor cell implantation, the fraction of administered ${ }^{3} \mathrm{H}$-mannitol present in the capillary pellet was approximately 0.005 (Fig. 3A). Furthermore, there were no differences in ${ }^{3} \mathrm{H}$-mannitol content in the capillary fractions taken from the right (tumor bearing) versus left (non-tumor bearing) brain hemispheres from day 7 and day 10 mice (Fig. 3A). However, by day 12, there was a slight but significant (p value $=0.04$ ) increase in ${ }^{3} \mathrm{H}$-mannitol content in the capillary fraction from the right hemisphere compared to that observed in the left hemisphere (Fig. 3A). Differences in radiolabeled mannitol content in the vascular pellet was even greater at day 15 post tumor cell implantation, with an almost two-fold increase in radiolabeled mannitol content from the right hemisphere capillary fraction compared to the left hemisphere ( $p$ value $=0.008$ ) (Fig. 3A). Similar data were obtained with protein content in the capillary fractions from the right and left brain hemispheres with significant enhancement in protein observed within the right hemisphere capillary pellet at day 12 and 15 post tumor cell implantation (Fig. 3B).

\section{Permeability Assessment in Brain and Tumor Microvasculature}

Blood-brain barrier permeability was examined at various stages of tumor development using both small molecule ( ${ }^{3} \mathrm{H}$-mannitol) and large molecule (Evan's Blue) permeability markers. In the sham operated mice, ${ }^{3} \mathrm{H}$-mannitol had a brain-to-plasma ratio of approximately 5\% in both the right and left brain hemispheres (Fig. 4). The amount of radiolabeled mannitol present in the left (non-tumor bearing) hemisphere from tumor cell injected mice was similar to that found in the sham operated mice at all time points examined (Fig. 4). There were no significant differences observed in radiolabeled mannitol permeability in the right (tumor-bearing) hemisphere compared to the left hemisphere in mice at 7 -day $(\mathrm{p}=0.102)$ and 10 -day $(\mathrm{p}=0.06)$ post tumor cell implantation (Fig. 4). However, there was a statistically significant increase in ${ }^{3} \mathrm{H}$-mannitol permeability observed in the right hemisphere in mice by 12 -days $(\mathrm{p}=0.004)$ post tumor cell implantation (Fig. 4). By 15-day post tumor cell implantation, there was an even greater increase in ${ }^{3} \mathrm{H}$-mannitol permeability (approximately 2-fold) in the right hemisphere compared to the left hemisphere (Fig. 4). Despite the increases in ${ }^{3} \mathrm{H}$-mannitol penetration observed in the tumor bearing portion of the brain, quantitative assessment of Evan's Blue accumulation in the capillary depleted fractions from both right and left hemispheres were comparable to the sham mice at all time points examined (data not shown).

Similar results were obtained using Gad-DTPA enhanced MRI to assess BBB integrity. Representative images of Gad-DTPA from mice at various stages of tumor development are shown in Figure 5A. Quantitative assessment of percent enhancement of MR image following Gad-DTPA injection in tumor bearing mice at 7-day was similar to that observed in sham operated mice. However, by day 12 of tumor cell implantation, there was visible leakage observed in all the mice examined. The mean percent enhancement of MR images in the tumor mice at 12-day was approximately 3 -fold higher than the control mice (Fig. 5B). An even larger area of Gad-DTPA leakage was observed by 15-day post tumor cell implantation with a 9-fold increase in tumor bearing mice compared to control mice (Fig. 5B). The extent of the changes in cerebral microvessel permeability was further assessed in the tumor region and compared to that in non-tumor brain tissue as well as the circumventricular organs (CVO) residing around the lateral ventricle that lie outside of the BBB. There were approximately 10-fold increases in Gad-DTPA intensity within the tumor region compared to non-tumor regions in the contralateral hemisphere observed at both 12 
and 15-days post tumor cell implantation, however, this was still significantly less ( $\mathrm{p}=$ 0.041 and $\mathrm{p}=0.050$, respectively) than Gad-DTPA enhancement within the ventricles (Fig. $5 \mathrm{C})$.

\section{P-glycoprotein expression}

To examine tumor-dependent alterations in P-gp expression in the microvasculature of the brain, western blots were performed using capillary enriched fractions of the tumor injected mouse brains at day 7,10,12, and 15 days post-tumor cell inoculation, and in sham mice at day 15 (Fig. 6). Examination of P-glycoprotein (P-gp) expression in the capillary enriched fractions indicated no statistical differences in P-gp expression in the tumor containing hemisphere compared to the non-tumor bearing hemisphere at any of the days examined (Fig. 6B). Immunhistochemical examination of the brain slices showed strong P-gp staining within the cerebral microvasculature with no apparent difference in P-gp staining in tumor versus non-tumor sections (Data not shown).

\section{DISCUSSION}

The incidence of metastases to the brain is approximately $10 \%$ for all cancer patients [12], with lung, breast and melanoma having the highest rate of occurrence [13, 14]. In the case of lung tumor, metastases to the brain are a frequent complication present in $10 \%$ of patients at time of diagnosis and in approximately $40 \%$ of all lung cancer patients during the course of their disease [15]. Treatment of lung metastases to the brain has focused primarily on whole brain radiation therapy and surgery [16]. Radiosurgical approaches also provide a noninvasive treatment option for treating metastatic brain tumors [17, 18]. However, regardless of the various treatment options, prognosis and long-term survival for metastatic brain tumors remain poor [19]. Chemotherapeutic options for treating metastatic brain tumors are limited and primarily reserved for clinical trials [20].

The role of the BBB in the limited chemotherapeutic responses of brain tumors remains a fundamental issue. In the clinical setting, studies by Vogelbaum and colleagues measured the extravasation of S100beta, an astrocytic protein, into serum as a potential biomarker for brain tumors. The study consisted of 38 patients with newly diagnosed lung carcinoma and no neurologic symptoms or known history of brain metastasis [21]. The study demonstrated significantly elevated levels of $S 100 \beta$ in serum, which would suggest that BBB integrity is compromised in these patients [21]. This is consistent with other studies demonstrating that tumor cells infiltrating peritumoral brain tissue caused histological changes within the blood vessels resulting in structural characteristics associated with a leaky vasculature [22].

However, there is no clear consensus on BBB permeability within and around the tumor site. Studies by Regina et al., reported that specific morphological characteristics of the BBB were maintained at the cellular level in brain tumor [23].

Perhaps the most convincing argument for the BBB having a role in the limited effectiveness of chemotherapeutic agents in treating most brain tumors is the observation that the same tumor cell that is resistant to chemotherapeutics when found in the brain is significantly responsive when located at sites outside the brain [24]. This is re-enforced in the studies by Wolff et al. [25] examining the in vitro cytotoxicity of a large panel of chemotherapeutic agents in various human, rat, and mouse glioma cells. Even in the most resistant cells, substantial cytotoxicity was observed with chemotherapeutic agents that are normally ineffective in the clinical treatment of brain tumors. Furthermore, BCNU, an agent commonly used clinically to treat brain tumors was among the least effective of all the chemotherapeutics examined in the in vitro cytotoxicity studies. This suggests the resistance of brain tumors to chemotherapeutic agents is due, in large part, from the failure to obtain appropriate therapeutic concentrations of the drugs in the brain. Indeed, a retrospective 
evaluation of tumor responsiveness to chemotherapeutic agents found a favorable response to chemotherapy was only around $45 \%$ in patients with small cell lung cancer brain metastases. One of the main contributing factors to the low response rate was inaccessibility to anti-cancer agents due to the blood-brain-barrier (BBB) [22]. Thus these studies suggest that $\mathrm{BBB}$ integrity remains intact, at least to the extent that significant delivery of chemotherapeutic agents is compromised, and that improving the permeability of chemotherapeutic agents in the BBB may have a substantial impact on the treatment of brain tumors.

The goal of the present study was to evaluate BBB permeability throughout various stages of tumor growth in a murine brain tumor model relevant to metastatic brain tumors. The model consisted of Lewis Lung carcinoma cells (3LL) implanted directly into the brain of $\mathrm{Balb} / \mathrm{c}$ mice. In the present study, the resulting brain tumor progressed rapidly with a median survival time of 17 days and with none of the mice surviving past 19 days. Histological examination and MRI indicated the tumor progresses as a relatively defined mass with no micrometastases observed. The 3LL tumor cell line is a lung carcinoma originally isolated from the C57BL/6 mouse strain [26]. However implanting 3LL cells into allogeneic recipients, including Balb/c, allows assessment of local tumor development at the site of implantation without spontaneous metastases to other tissue [27]. Interestingly, this is not due to lack of migration of the cells from the primary site, but to immunogenetic restrictions in tumor development within the allogeneic host. The model used in the current study differs from other metastatic models in which the tumor cells are injected either via the left ventricle or carotid artery [28-30]. While the other models are invaluable for examination of mechanisms for cell migration and metastasis in the brain, the rate and number of brain metastasis is variable and confounded by the potential development of metastatic tumors at peripheral sites. Given the focus of the present study, the intracranial implantation of 3LL cells into Balb/c mice was selected to examine tumor induced alterations in BBB function and the implications of this from a drug delivery standpoint.

The present study examined BBB permeability during various stages of tumor progression using two complimentary methods. The first method used radiolabeled small molecule tracer, ${ }^{3} \mathrm{H}$-mannitol and large macromolecule tracer dye, Evan's blue, to assess permeability alterations. For the small molecule tracer, the current study shows that the BBB remains intact early on in tumor progression (up to 10 days post tumor cell implantation), and becomes leaky only after tumor mass has progressed to approximately $10 \mathrm{~mm}^{3}$ or more (i.e 12-day post tumor cell implantation and beyond). However, even though BBB integrity to the small hydrophilic vascular permeability agent was significantly altered at the later stages of tumor development, permeability to Evan's blue, a dye that binds with high affinity to albumin, remained unchanged. This suggests that although tight junctions are disrupted, the wholesale breakdown of BBB integrity observed with other CNS pathologies does not occur in this particular brain tumor model.

These findings were confirmed using MRI techniques to monitor BBB permeability during tumor progression. In the present study Gad-DTPA enhanced contrast agent was used to quantitatively measure BBB changes during tumor progression. There was essentially no Gad-DTPA contrast agent observed in the brains of the sham operated mice, indicating that the surgical implantation of tumor cells did not lead to vascular leakage. Likewise, there was no Gad-DTPA contrast agent observed in the brains of tumor bearing mice at 7 days post tumor implantation, suggesting no alterations in BBB permeability at this early stage of tumor development. However, there was significant enhancement of the Gad-DTPA contrast agent in the brain of tumor mice at 12 and 15-days post tumor cell implantation. 
Interestingly, the changes in BBB permeability observed in tumors at the later stages of development in the present study occurred along the same time frame as increased angiogenesis within the tumor. At the most advanced stages of tumor development examined (i.e. day 15) there was an approximately 2 -fold increase in cerebral microvasculature volume. This increase coincides with the dramatic enhancement in BBB permeability observed in the tumor regions at day 15 . The $3 \mathrm{LL}$ tumor metastases to the brain are characterized by increased angiogenesis to support tumor growth [31]. This is consistent with other metastatic brain tumor models. For instance, studies indicated that the BBB was intact in the early stages of human metastatic brain tumor growth in nude mice [32]. In these studies in which human breast cancer cells were implanted in the brain, it was observed that, the $\mathrm{BBB}$ remained intact in tumors smaller than $0.25 \mathrm{~mm}$ in diameter, but was leaky in larger metastases [32]. A similar finding of alterations in BBB permeability as a function of tumor progression have also been demonstrated in studies using a mouse melanoma metastatic brain tumor model [33]. Together these studies highlight the impact of tumor development on BBB permeability in metastatic brain tumor models.

Gadolinium enhanced contrast MRI is commonly used clinically to examine BBB integrity and identify brain tumors with enhanced vascular permeability [34]. Additional advantages of using MRI and Gad-DTPA enhanced contrast agent to assess BBB permeability in the current study was the ability to monitor permeability changes within the same animal and the ability to examine regional differences in BBB permeability. Thus, while Gad-DTPA contrast revealed significant leakage within the tumor site, as much as 9-fold enhancement by day 15 post-tumor cell implantation, there was little if any enhancement observed outside of the tumor margins. These findings, together with the radiolabeled mannitol permeability assessments in the right and left hemispheres, suggest that the alterations in BBB permeability observed during later stages of tumor development are confined to regions within the tumor itself. The implication of this finding is that the presence of an intact BBB surrounding the tumor would create a substantial concentration gradient between the tumor and non-tumor regions of the brain. As a result of the concentration gradient, there would be diffusion of the chemotherapeutic agent away from the tumor into non-tumor sites of lower concentration. Furthermore, while the tumor vasculature was leaky compared to the normal $\mathrm{BBB}$, the magnitude of Gad-DTPA contrast enhancement observed in the tumor regions was still significantly less than the ventricle regions that lie outside the BBB (Fig. 5C). Thus, the present studies indicate that despite the apparent leakiness of the tumor vasculature, there are still barrier properties that would restrict drug permeability in the brain tumor. These findings are consistent with those of Lockman and colleagues (2010) demonstrating that even in breast cancer metastatic brain tumor models with disrupted BBB function, the resulting concentration of therapeutic agents within the tumor site were sub-optimal for effecting tumor growth. These studies highlight the importance of an intact BBB around the tumor site and suggest the resistance of brain tumors, even relatively leaky brain tumors, to chemotherapeutic agents may stem from the failure to obtain appropriate therapeutic concentrations of the drugs throughout the brain.

The increases in BBB permeability of radiolabeled mannitol and Gad-DTPA contrast agent observed in the later stages of brain tumor development are consistent with a breakdown of the tight junction complexes of the brain endothelial cells that limit paracellular diffusion. Indeed, both Gad-DTPA and radiolabeled mannitol are hydrophilic solutes with low BBB permeability under normal conditions and no known transporter interactions at the BBB. This is in contrast to many chemotherapeutic agents that are hydrophobic in nature and rely primarily on transcellular diffusion and transport processes for entry into the brain. Thus in addition to tight junctional complexes that act to restrict paracellular diffusion, the expression of drug efflux transporters at the BBB and the brain tumor barrier (BTB) may also limit distribution of chemotherapeutic agents in the brain [35]. The most extensively 
studied drug efflux transporter in the BBB is P-gp. As P-gp transports a variety of drugs, its expression within the brain endothelial cells forming the $\mathrm{BBB}$ could impact on a wide range of chemotherapeutic agents [36]. Indeed, using a mouse glioblastoma brain tumor model, Fellner and colleagues reported that systemic administration of paclitaxel, a P-gp substrate, did not affect tumor volume. However, co-administration of paclitaxel (intravenous) and PSC833, an inhibitor of P-gp, resulted in significant reductions in tumor volume in treated mice by $90 \%$ [37]. Thus, $\mathrm{P}$-gp is an important obstacle preventing paclitaxel entry into the brain, and inhibition of this transporter allows the drug to reach sensitive tumors within the CNS [37]. These findings are consistent with a role for P-gp in the resistance of some brain tumors to chemotherapy agents [38].

Given the important contribution of P-gp in restricting chemotherapeutic permeability in the $\mathrm{BBB}$, an additional concern is the potential influence of tumor progression on $\mathrm{P}$-gp expression within the BBB. Recent studies indicate down regulation of drug efflux transporter expression in cerebral vascular cells within the tumor regions of patients with primary central nervous system lymphoma [39]. In contrast, an increased expression of drug efflux transporters have been reported in other CNS tumors such as ependymomas [40]. In the 3LL brain tumor model used in the present study, P-gp expression was observed throughout brain tumor development. As P-gp was not expressed in the tumor cells, the main source is likely the brain capillary endothelial cells. While additional studies are required, initial assessment suggests $\mathrm{P}$-gp expression is similar in both the normal $\mathrm{BBB}$ and the BTB. These findings indicate that even at the later stages when BBB permeability is compromised, P-gp is likely to be functional and may limit chemotherapeutic delivery to the tumor site. Future studies with P-gp imaging agents should provide important information concerning P-gp function in the BBB and BTB sites.

In summary, we have successfully established a brain tumor model in mice using 3LL cells. In this model, the BBB was intact at the initial stages of brain tumor development (Fig. 4 and 5) with significant increases in BBB permeability only observed at the later stages as tumor mass increased. Furthermore, there were no changes in P-gp expression within the BBB at any of the time points examined following tumor cell implantation (Fig. 6). Based on these findings it would appear that modification of BBB permeability either through barrier disruption techniques [41-43] or pharmacological inhibition of drug efflux transporters could have a favorable impact on brain tumor responsiveness to chemotherapeutic agents.

\section{Acknowledgments}

These studies were supported by research grants from National Institutes of Health (CA-93558) and the Manitoba Health Research Council (MRC). Fellowship support for N.O. and R.M. were provided by MHRC. G.M.H. is a Canada Research Chair in Molecular Cardiolipin Metabolism.

\section{References}

1. Chan AW, Loeffler JS. Controversies in the management of patients with brain metastases. Cancer J. 2001; 7(2):105-107. [PubMed: 11324762]

2. Wong ET, Berkenblit A. The role of topotecan in the treatment of brain metastases. Oncologist. 2004; 9(1):68-79. [PubMed: 14755016]

3. Cohen MH, Matthews MJ. Small cell bronchogenic carcinoma: a distinct clinicopathologic entity. Semin Oncol. 1978; 5(3):234-243. [PubMed: 211637]

4. Bart J, Groen HJ, Hendrikse NH, van der Graaf WT, Vaalburg W, de Vries EG. The blood-brain barrier and oncology: new insights into function and modulation. Cancer Treat Rev. 2000; 26(6): 449-462. [PubMed: 11139374]

5. Goldstein GW, Betz AL. The blood-brain barrier. Sci Am. 1986; 255(3):74-83. [PubMed: 3749857] 
6. Loscher W, Potschka H. Blood-brain barrier active efflux transporters: ATP-binding cassette gene family. NeuroRx. 2005; 2(1):86-98. [PubMed: 15717060]

7. Loscher W, Potschka H. Role of drug efflux transporters in the brain for drug disposition and treatment of brain diseases. Prog Neurobiol. 2005; 76(1):22-76. [PubMed: 16011870]

8. Wiranowska M, Gonzalvo AA, Saporta S, Gonzalez OR, Prockop LD. Evaluation of blood-brain barrier permeability and the effect of interferon in mouse glioma model. J Neurooncol. 1992; 14(3): 225-236. [PubMed: 1281226]

9. Fidler IJ, Yano S, Zhang RD, Fujimaki T, Bucana CD. The seed and soil hypothesis: vascularisation and brain metastases. Lancet Oncol. 2002; 3(1):53-57. [PubMed: 11905606]

10. Benarroch EE. Circumventricular organs: receptive and homeostatic functions and clinical implications. Neurology. 2011; 77(12):1198-1204. [PubMed: 21931109]

11. Triguero D, Buciak J, Pardridge WM. Capillary depletion method for quantification of blood-brain barrier transport of circulating peptides and plasma proteins. J Neurochem. 1990; 54(6):18821888. [PubMed: 2338547]

12. Nayak L, Lee EQ, Wen PY. Epidemiology of brain metastases. Curr Oncol Rep. 2012; 14(1):4854. [PubMed: 22012633]

13. Giglio P, Gilbert MR. Neurologic complications of cancer and its treatment. Curr Oncol Rep. 2010; 12(1):50-59. [PubMed: 20425608]

14. Kamar FG, Posner JB. Brain metastases. Semin Neurol. 2010; 30(3):217-235. [PubMed: 20577929]

15. Schuette W. Treatment of brain metastases from lung cancer: chemotherapy. Lung Cancer. 2004; 45(Suppl 2):S253-S257. [PubMed: 15552807]

16. Taimur S, Edelman MJ. Treatment options for brain metastases in patients with non-small- cell lung cancer. Curr Oncol Rep. 2003; 5(4):342-346. [PubMed: 12781078]

17. Wowra B, Muacevic A, Tonn JC. CyberKnife radiosurgery for brain metastases. Prog Neurol Surg. 2012; 25:201-209. [PubMed: 22236681]

18. Kawabe T, Phi JH, Yamamoto M, Kim DG, Barfod BE, Urakawa Y. Treatment of brain metastasis from lung cancer. Prog Neurol Surg. 2012; 25:148-155. [PubMed: 22236676]

19. Nieder C, Grosu AL, Spanne O, Andratschke NH, Geinitz H. Brain metastases in patients under 50 years of age: retrospective analysis. Clin Exp Metastasis. 2012 May 27.

20. Kim KH, Lee J, Lee JI, Nam do H, Kong DS, Ahn YC, et al. Can upfront systemic chemotherapy replace stereotactic radiosurgery or whole brain radiotherapy in the treatment of non-small cell lung cancer patients with asymptomatic brain metastases? Lung Cancer. 2010; 68(2):258-263. [PubMed: 19592127]

21. Vogelbaum MA, Masaryk T, Mazzone P, Mekhail T, Fazio V, McCartney S, et al. S100beta as a predictor of brain metastases: brain versus cerebrovascular damage. Cancer. 2005; 104(4):817824. [PubMed: 15971200]

22. Stewart PA, Hayakawa K, Farrell CL, Del Maestro RF. Quantitative study of microvessel ultrastructure in human peritumoral brain tissue. Evidence for a blood-brain barrier defect. J Neurosurg. 1987; 67(5):697-705. [PubMed: 3668638]

23. Regina A, Demeule M, Laplante A, Jodoin J, Dagenais C, Berthelet F, et al. Multidrug resistance in brain tumors: roles of the blood-brain barrier. Cancer Metastasis Rev. 2001; 20(1-2):13-25. [PubMed: 11831641]

24. Weiss L. Metastasis: differences between cancer cells in primary and secondary tumors. Pathobiol Annu. 1980; 10:51-81. [PubMed: 7443292]

25. Wolff JE, Trilling T, Molenkamp G, Egeler RM, Jurgens H. Chemosensitivity of glioma cells in vitro: a meta analysis. J Cancer Res Clin Oncol. 1999; 125(8-9):481-486. [PubMed: 10480340]

26. Talmadge JE, Fidler IJ. Enhanced metastatic potential of tumor cells harvested from spontaneous metastases of heterogeneous murine tumors. J Natl Cancer Inst. 1982; 69(4):975-980. [PubMed: 6750200]

27. Isakov N, Feldman M, Segal S. An immune response against the alloantigens of the 3LL Lewis lung carcinoma prevents the growth of lung metastases, but not of local allografts. Invasion Metastasis. 1982; 2(1):12-32. [PubMed: 6765248] 
28. Conley FK. Development of a metastatic brain tumor model in mice. Cancer Res. 1979; 39(3): 1001-1007. [PubMed: 427739]

29. Zhang Z, Hatori T, Nonaka H. An experimental model of brain metastasis of lung carcinoma. Neuropathology. 2008; 28(1):24-28. [PubMed: 18181831]

30. Taskar KS, Rudraraju V, Mittapalli RK, Samala R, Thorsheim HR, Lockman J, et al. Lapatinib distribution in HER2 overexpressing experimental brain metastases of breast cancer. Pharm Res. 2012; 29(3):770-781. [PubMed: 22011930]

31. Fathallah-Shaykh HM, Zhao LJ, Kafrouni AI, Smith GM, Forman J. Gene transfer of IFN-gamma into established brain tumors represses growth by antiangiogenesis. J Immunol. 2000; 164(1):217222. [PubMed: 10605014]

32. Zhang RD, Price JE, Fujimaki T, Bucana CD, Fidler IJ. Differential permeability of the bloodbrain barrier in experimental brain metastases produced by human neoplasms implanted into nude mice. Am J Pathol. 1992; 141(5):1115-1124. [PubMed: 1443046]

33. Cranmer LD, Trevor KT, Bandlamuri S, Hersh EM. Rodent models of brain metastasis in melanoma. Melanoma Res. 2005; 15(5):325-356. [PubMed: 16179861]

34. Essig M, Weber MA, von Tengg-Kobligk H, Knopp MV, Yuh WT, Giesel FL. Contrastenhanced magnetic resonance imaging of central nervous system tumors: agents, mechanisms, and applications. Top Magn Reson Imaging. 2006; 17(2):89-106. [PubMed: 17198225]

35. Rice A, Michaelis ML, Georg G, Liu Y, Turunen B, Audus KL. Overcoming the bloodbrain barrier to taxane delivery for neurodegenerative diseases and brain tumors. J Mol Neurosci. 2003; 20(3): 339-343. [PubMed: 14501017]

36. Bachmeier CJ, Spitzenberger TJ, Elmquist WF, Miller DW. Quantitative assessment of HIV-1 protease inhibitor interactions with drug efflux transporters in the blood-brain barrier. Pharm Res. 2005; 22(8):1259-1268. [PubMed: 16078135]

37. Fellner S, Bauer B, Miller DS, Schaffrik M, Fankhanel M, Spruss T, et al. Transport of paclitaxel (Taxol) across the blood-brain barrier in vitro and in vivo. J Clin Invest. 2002; 110(9):1309-1318. [PubMed: 12417570]

38. Henson JW, Cordon-Cardo C, Posner JB. P-glycoprotein expression in brain tumors. J Neurooncol. 1992; 14(1):37-43. [PubMed: 1361524]

39. Sakata S, Fujiwara M, Ohtsuka K, Kamma H, Nagane M, Sakamoto A, et al. ATPbinding cassette transporters in primary central nervous system lymphoma: decreased expression of MDR1 Pglycoprotein and breast cancer resistance protein in tumor capillary endothelial cells. Oncol Rep. 2011; 25(2):333-339. [PubMed: 21165575]

40. Ginguene C, Champier J, Maallem S, Strazielle N, Jouvet A, Fevre-Montange M, et al. Pglycoprotein (ABCB1) and breast cancer resistance protein (ABCG2) localize in the microvessels forming the blood-tumor barrier in ependymomas. Brain Pathol. 2010; 20(5):926-935. [PubMed: 20406235]

41. Hall WA, Doolittle ND, Daman M, Bruns PK, Muldoon L, Fortin D, et al. Osmotic blood-brain barrier disruption chemotherapy for diffuse pontine gliomas. J Neurooncol. 2006; 77(3):279-284. [PubMed: 16314949]

42. Meairs S, Alonso A. Ultrasound, microbubbles and the blood-brain barrier. Prog Biophys Mol Biol. 2007; 93(1-3):354-362. [PubMed: 16959303]

43. Sato S, Kawase T, Harada S, Takayama H, Suga S. Effect of hyperosmotic solutions on human brain tumour vasculature. Acta Neurochir (Wien). 1998; 140(11):1135-1141. disc 1141-2. [PubMed: 9870058] 


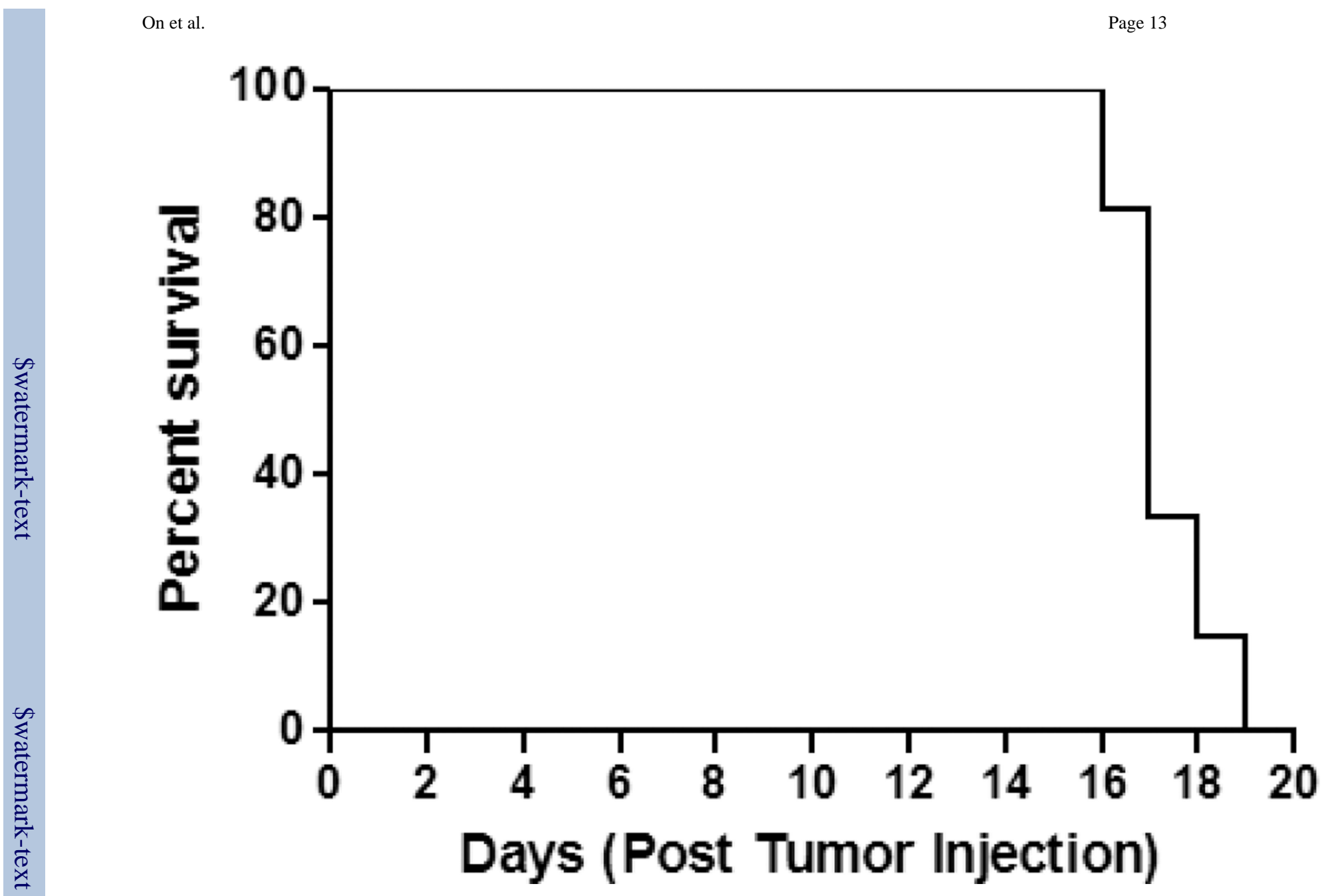

Fig. 1.

Survival studies in tumor injected mouse. All the mice survived till day 15 post tumor injection but none survived past day 19 as a result the mean survival time was day 17 post tumor injection. $(\mathrm{n}=7)$ 


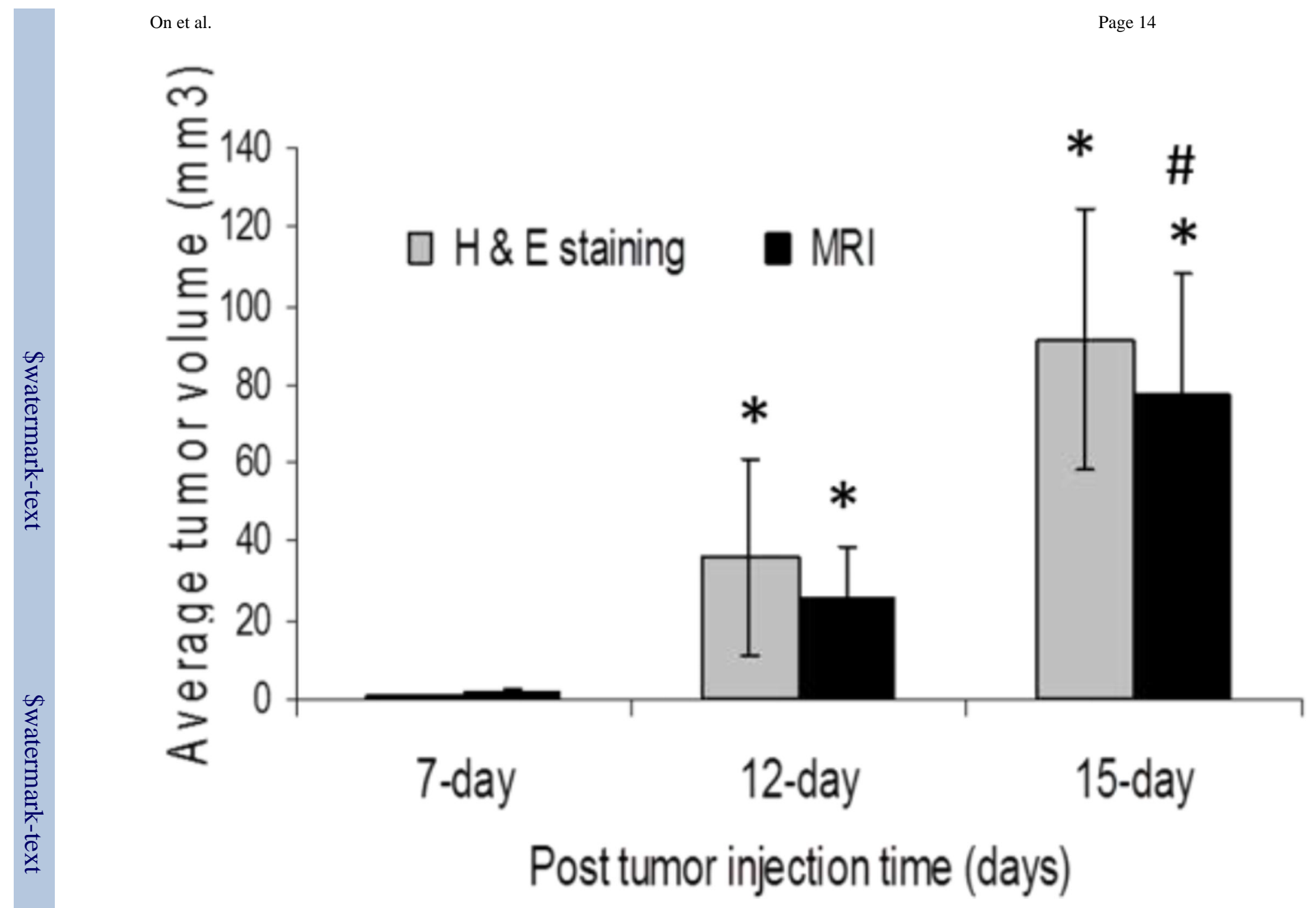

Fig. 2.

Tumor volume on day 7, 12, and 15 post 3-LL tumor cell injection in femal Balb/c mice using both H\&E staining and T2-weighted MRI. The data is represented as mean \pm sem, $n=3$ for each time point. ${ }^{*} \mathrm{p}<0.05$ compared to day 7 tumor mice within same group; $\# \mathrm{p}<0.05$ compared to day 12 tumor mice within same group as assessed by ANOVA. 
A

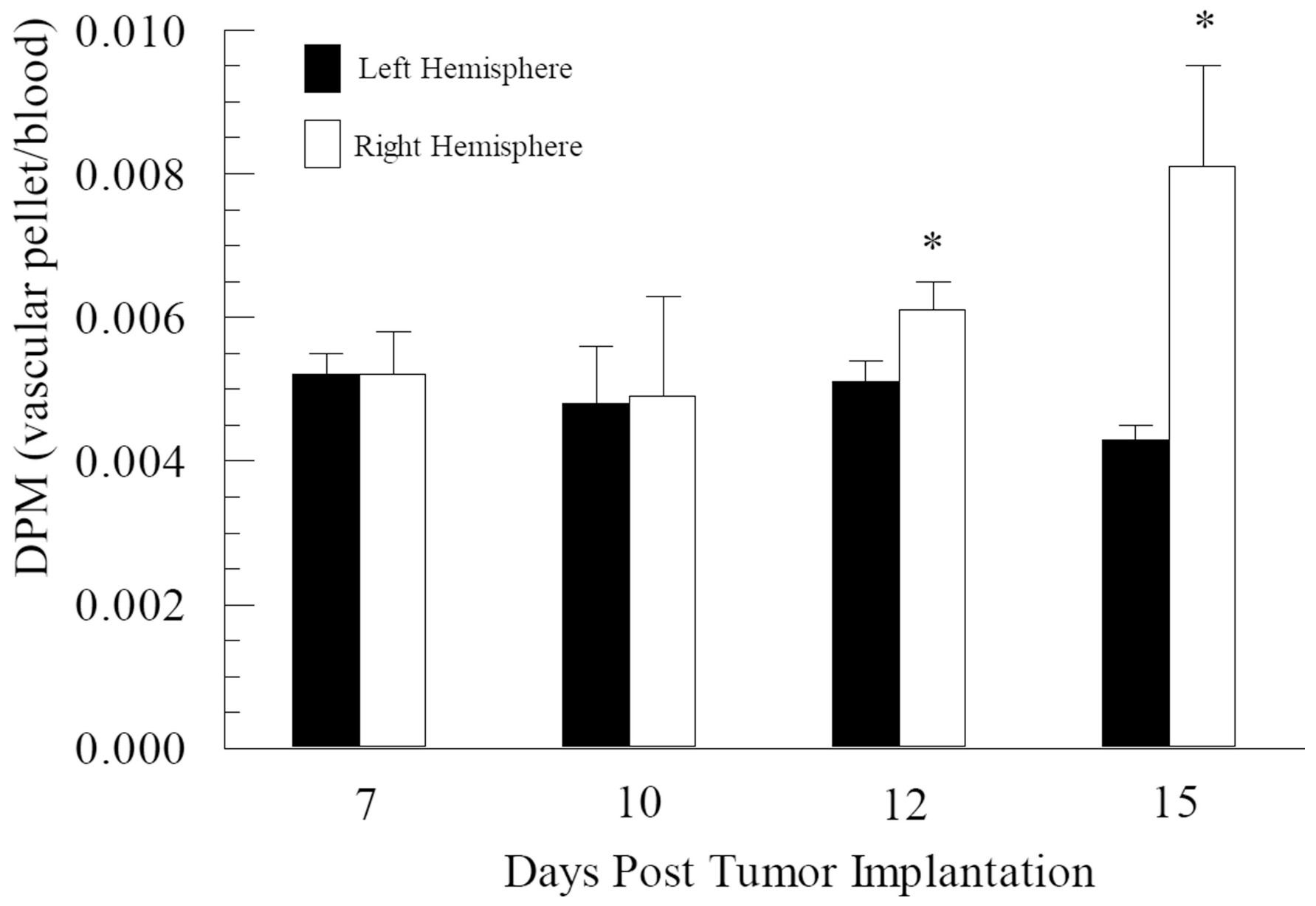




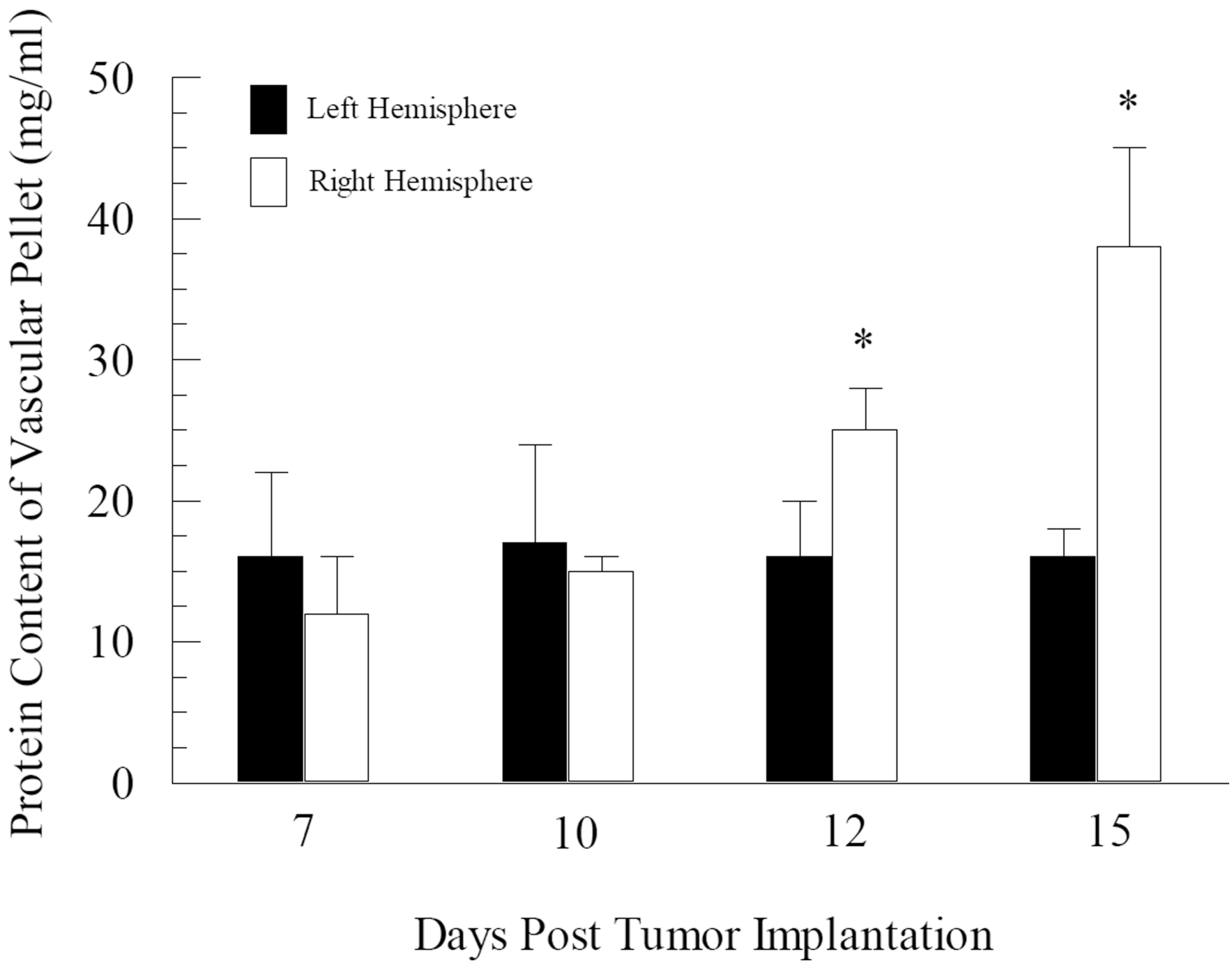

Fig. 3.

Changes in cerebral vascular volume in mice as a function of brain tumor development. Mice at different stages of brain tumor development were given i.v. injections of radiolabelled mannitol. The brains were removed and separated into right (tumor-bearing) and left (non-tumor bearing) hemispheres and capillary depletion was performed. Vascular volume was assessed based on radioactivity (Panel A) and protein content (Panel B) of the capillary pellet. Values represent the mean \pm SEM of 6 mice. $* p<0.05$ compared to left hemisphere at same day as assessed using Student paired t-test. 


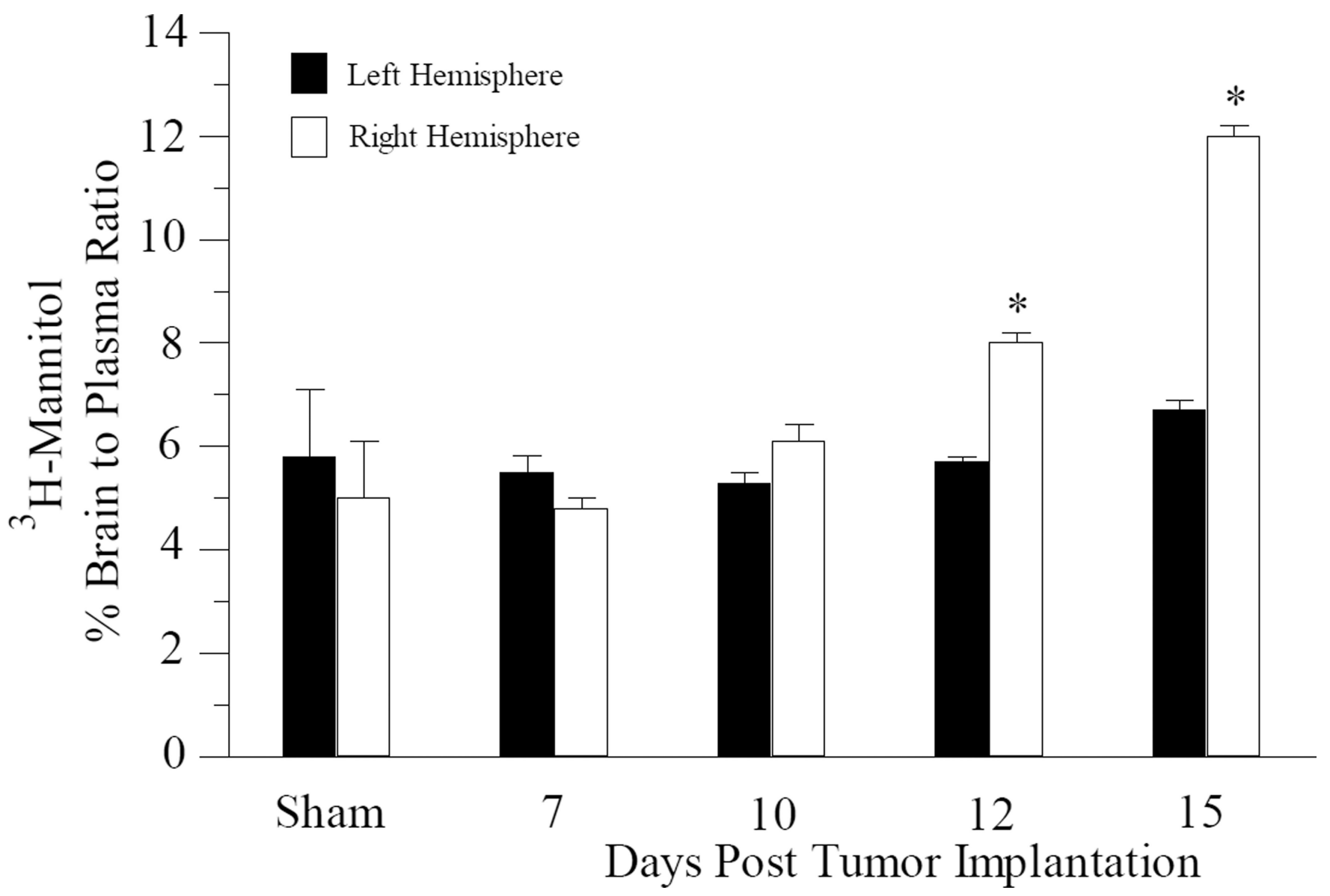

Fig. 4.

Permeability of radiolabelled mannitol across the blood brain barrier in tumor bearing mice. Mice at different stages of tumor development were given i.v. injections of radiolabelled mannitol. Animals were sacrificed and the brain separated into right (tumor-bearing) and left (non-tumor bearing) hemispheres. The data are presented as the percent brain to plasma ratio of the resulting radioactivity. Each data point is the mean \pm s.e.m of at least $6-8$ mice. ${ }^{*} \mathrm{p}<$ 0.05 compared to left hemisphere at same day as assessed using Student paired t-test. 
A

Day 7

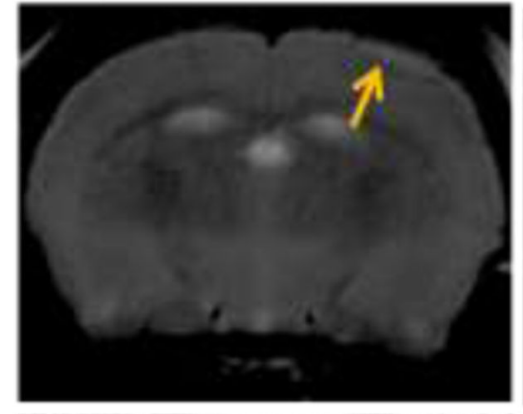

T2-weighted image

\% enhanced MR images

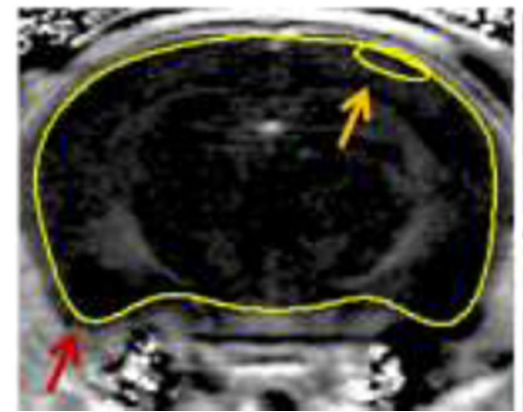

Day 12
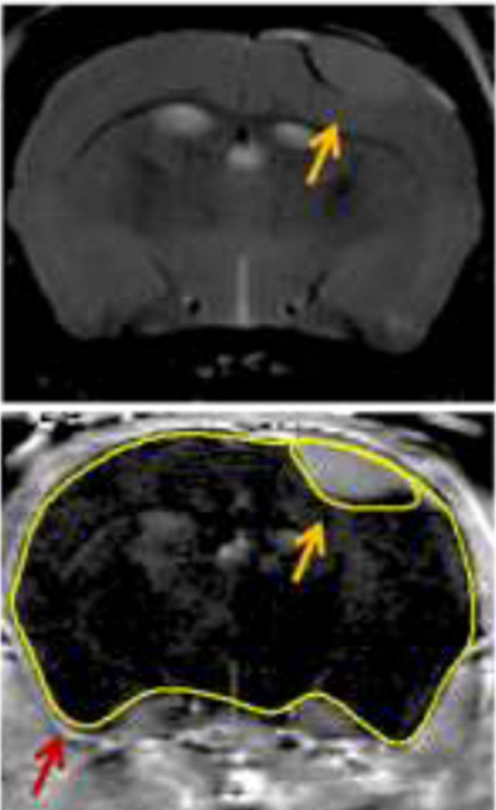

Day 15
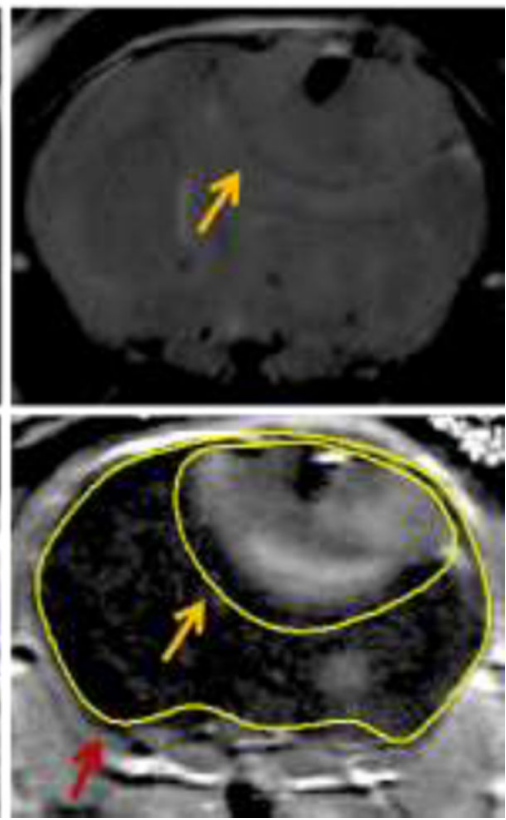

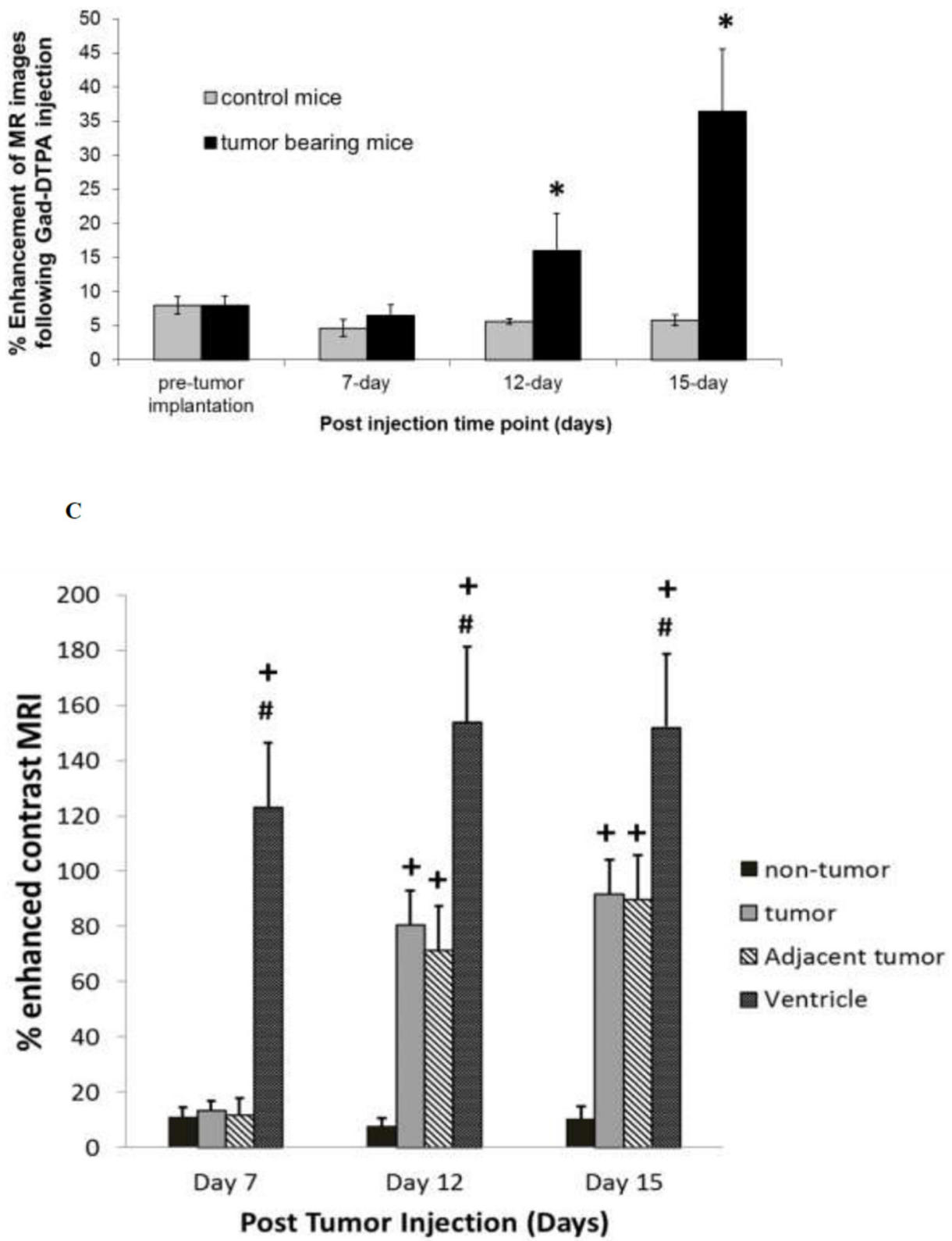

Fig. 5.

Enhancement of MR images following Gad-DTPA injection in brain and brain tumor mice. Panel A - Representative of \% enhanced MR images from a tumor bearing mouse at day 7, day 12 and day 15 post tumor cell implantation. Images are from the same mouse at a region near the initial tumor cell injection site. Tumor and brain region were determined from T2weighted images (Top Panel) and highlighted as indicated by the yellow and red arrows respectively. Panel B - Percent enhancement of MR images following Gad-DTPA at different time points after the induction of tumor compared to sham (control) mice. Panel C - Percent-enhanced Gad-DTPA MR images from various brain regions of interest in tumor bearing mice at different stages of tumor growth. Tumor area was determined from T2- 
weighted MRI. Non-tumor regions were taken from the contralateral hemisphere as well as circumventricular regions around the third ventricle. Each data point is the mean \pm SEM of 4-8 mice. Data from tumor and control mice as well as from various areas of interest within tumor mice were analyzed using ANOVA, $* \mathrm{p}<0.05$ compared to control mice; $+\mathrm{p}<0.05$ compared to non-tumor; \# $\mathrm{p}<0.05$ compared to tumor. 
A

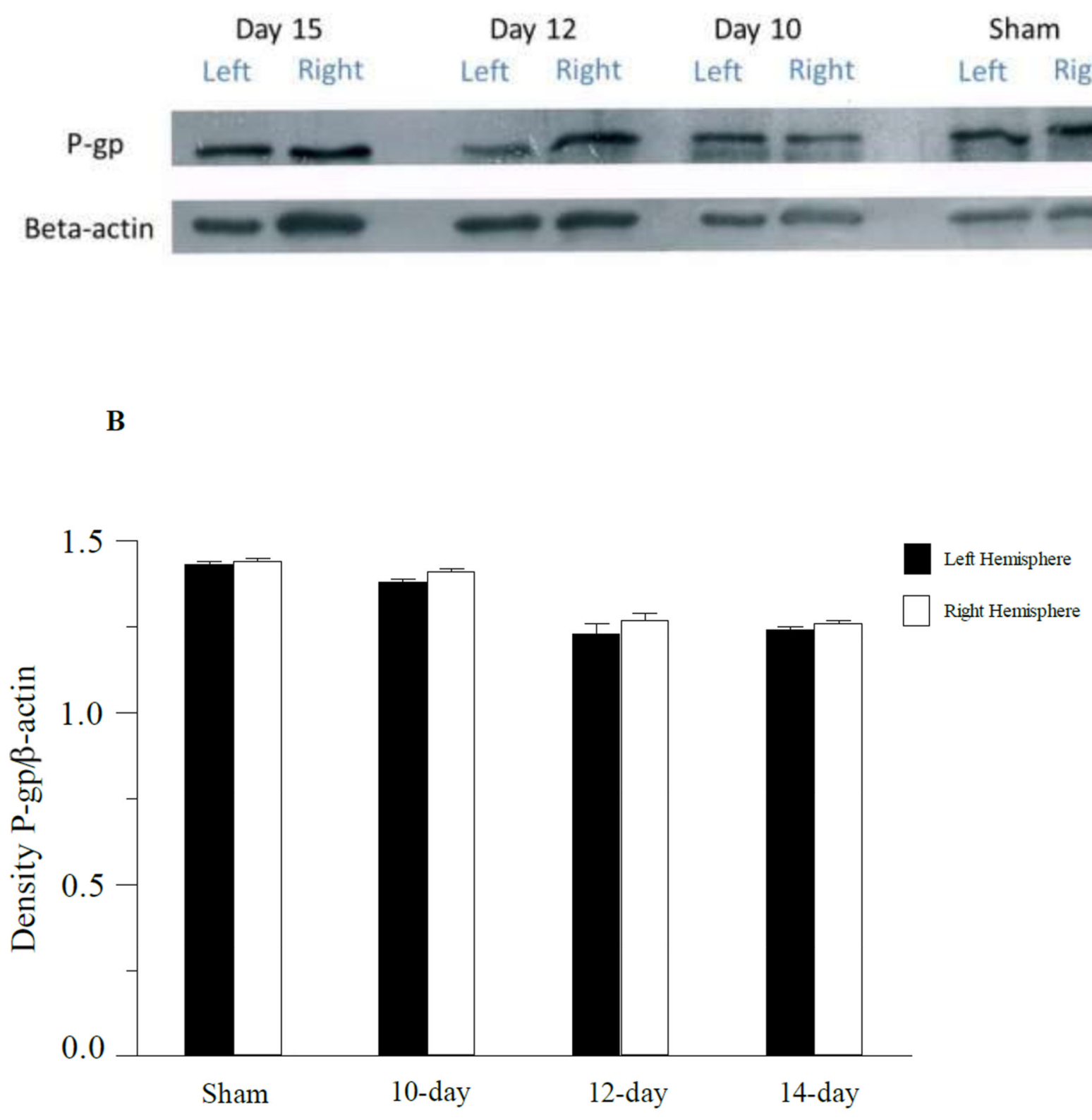

\section{Condition}

Fig. 6 .

Western blot of capillary enriched fractions from mice implanted with 3LL tumor cells at different times during tumor development. Panel A: Expression of P-gp and beta-actin in the left hemisphere and right hemisphere capillary enriched fractions from tumor injected mice on 15, 12 and 10-days post tumor injection. P-gp expression in the left and right hemispheres of sham operated mice (day 15) are also shown. Samples were pooled from 3 mice at each time point. Panel B: Densitometry analysis of the western blot samples for P-gp in capillaries from the left and right brain hemispheres. 